\title{
Research on the Influencing Factors of Teachers' Beliefs in Intelligent Education
}

\author{
Fei Shang \\ Faculty of Education, Beijing Normal University, Beijing 100875, China.
}

\author{
How to cite this paper: Fei Shang. (2021) \\ Research on the Influencing Factors of \\ Teachers' Beliefs in Intelligent Education. \\ The Educational Review, USA, 5(8), \\ 287-294. \\ DOI: 10.26855/er.2021.08.005
}

Received: July 12, 2021

Accepted: August 8, 2021

Published: August 25, 2021

Corresponding author: Fei Shang, Faculty of Education, Beijing Normal University, Beijing 100875, China.

Email: sf81076@163.com

\begin{abstract}
With the education informatization entering the stage of 2.0, the focus of China's education technology has shifted from "informatization" to "intelligence", and the intelligent system has gradually integrated into the traditional classroom. However, most of the existing studies are based on the perspective of students' learning or intelligent platform construction, ignoring that teachers are the main driving force of technology application and traditional teaching methods. Based on the subjective perspective of the front-line teachers, this study is based on a questionnaire survey to understand teachers' teaching preparation for conducting intelligent teaching from different aspects, collect first-line teachers' feedback on artificial intelligence teaching beliefs and teaching practices, explore the influencing factors of teachers' beliefs and how they interact with each other, and adjust the teaching structure and point to artificial intelligence in the education of technological change. Teachers who can teach put forward development strategies to promote teachers from low-level information teaching ability to high-level intelligent teaching ability.
\end{abstract}

Keywords

Teachers’ Beliefs, Intelligent Teaching, Influence Factor, Teaching Practice

\section{The presentation of research problems}

\subsection{The tide of intelligent education is surging}

Intelligence education is a key part of the country's AI development strategy, which was issued in 2017. In 2018, the Ministry of Education released the "Education Informatization 2.0 Action Plan", indicating that education informatization has entered the 2.0 stage. In the document, it is proposed to apply artificial intelligence, big data and other intelligent technologies to the field of education, so as to realize the reconstruction of education mode under intelligent teaching. The emphasis of education technology in China has been transferred from "information" to "intelligent", and intelligent system is gradually integrated into traditional classroom. Zhu Zhiting et al. defined the connotation of intelligent education as: firstly, education supported by intelligent technology; secondly, education learning intelligent technology; thirdly, education promoting intelligent development (Zhu, 2018). This provides technical support for individualized learning and individualized learning. The earliest attempt to apply artificial intelligence technology to teaching can be traced back to the programmed teaching machine developed by B. F. Skinner in 1958. It can store and present textbooks, receive learners' answers and give feedback to strengthen learners' learning motivation. As a technology, artificial intelligence has entered the field of education and teaching, and is moving from external technical assistance to internal integration technology penetration (Guo, 2019). From the early computer-aided instruction (CAI) to the intelligent learning guidance system, educational robot, intelligent agent, etc., they show different application forms, such as the form of AI subjectivity integration, the form of AI auxiliary technology means and the form of AI functional 
embedding (Guo, 2020). Artificial intelligence subjectivity into form, such as problem solving, expert system, machine learning, natural language processing, logical reasoning and other key technology teaching, development of students' awareness of artificial intelligence, become the creator of technology; the second form of artificial intelligence auxiliary technology means, artificial intelligence technology is applied to teacher teaching, student learning and school management, without changing the structure of teaching itself, reshapes learners' learning experience and realizes the sharing of high-quality education resources. The third type of functional embedded form of artificial intelligence, artificial intelligence empowers teachers, and man-machine cooperation in teaching, changing the teaching structure itself. For example, the integration of artificial intelligence and information technology, English, Chinese and other subjects teaching. In various application forms, Artificial intelligence plays the role of teacher, peer and student in teaching.

The wave of intelligent education has promoted the popularity of a series of new words such as "learning situation analysis" and "data mining". At present, China's education reform is also in the new situation of diversified object groups, diversified social needs, and lifelong learning for all. Using artificial intelligence technology to solve the problems of education reform has become a hot topic of social concern.

\subsection{Teachers face the challenge of intelligent teaching}

Under the background of information 2.0 era, the application of artificial intelligence technology in education and teaching is increasingly rich, which changes the traditional education and teaching methods and promotes the development trend of the dual integration of online and offline education in the future. Artificial intelligence teaching in the form of integration of artificial intelligence technology and subject teaching, technology teaching and application of technology products is a new challenge and requirement for primary and secondary school teachers in the Times. At present, the application development of artificial intelligence teaching is not mature enough, and the ability of teachers to control artificial intelligence technology has not been developed. Artificial intelligence teaching becomes a formality and ignores human social and emotional education.

In the process of teaching, artificial intelligence has brought unprecedented impact to teachers, and the teaching mode, teaching methods, teaching objectives and teaching strategies chosen by teachers will change accordingly. Traditional educational and teaching ideas pay more attention to knowledge transmission, teachers often do not have enough time and energy to in-depth communication with students (Liu, 2018). However, with the application of artificial intelligence, students are no longer satisfied with teachers' generalization of theoretical knowledge, but pay more attention to experience and experience accumulation of practical learning knowledge. At present, although there are many researches focusing on application inevitability analysis, development status analysis, future application prospect, and discussion on THE role of AI and teachers, practical research lacks the feedback of teachers' subjective perspective on AI teaching beliefs and teaching practice, which is likely to lead to the disconnection between research and practice. It is difficult to clarify the cognitive status of front-line teachers for artificial intelligence technology and the problems and challenges faced by carrying out intelligent teaching.

The application of intelligent teaching system can make students get the information of the most cutting-edge field of knowledge content at any time. As a result, teachers' views may be questioned by students. Therefore, teachers need to constantly enrich their teaching knowledge and improve their professional level and quality. Teachers need to change their role positioning, reform education teaching methods, improve artificial intelligence teaching methods, strengthen the practicality of teaching, and reshape the new image of education.

\subsection{Research on teacher beliefs in intelligent teaching is scarce}

In the era of information 2.0, intelligent technology has entered the field of education, and the new curriculum reform has been progressing continuously. Researchers have conducted many researches on the in-depth teaching of information technology. The study of teachers' teaching beliefs in the context of information technology has gradually become an important aspect of the endogenous thinking of teacher image (Li, 2012). Many scholars at home and abroad believe that teacher belief is an important factor in teacher education and teaching. Based on this, the author in the CNKI advanced search mode, the teaching of "intelligent" or containing the search term "smart education" in the subject scope of the search, the literature category limit for II album I album and social science, social science database and the retrieval time are limited, a total of search to 311 references, further check the core journals, to search, 65 literatures were found. The related topic distribution is shown in Figure 1

As can be seen from the literature search, the cutting-edge research topics include "artificial intelligence", "intelligent teaching system", "artificial intelligence education" and "intelligent education”. There are few literatures based on the perspective of teachers. Researchers generally pay attention to the differences between teaching with intelligent technology and traditional teaching, and ignore the main role of teachers in teaching. The author searches "intelligent 
teaching" with "teaching beliefs" as the search term, and the search results are 0 literatures. This situation reminds us that we should pay more attention to the combination of intelligent technology and teaching from the perspective of teachers, understand teachers’ behaviors and explore teachers’ inner implicit beliefs about intelligent teaching.
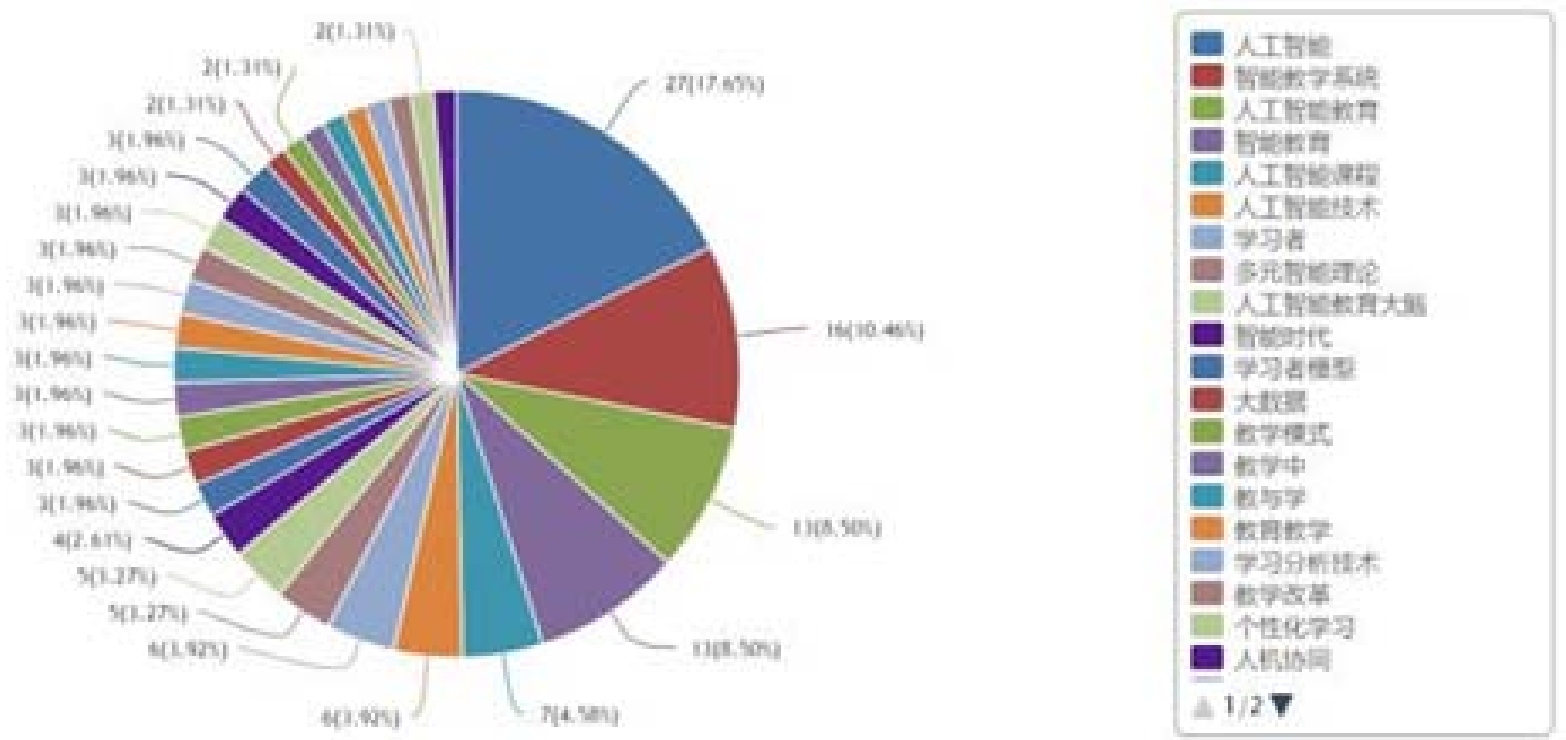

Figure 1. Artificial intelligence technology into education research topic distribution.

\section{Teacher beliefs in intelligent teaching: Connotation and characteristics}

\subsection{Teacher beliefs in intelligent teaching: Connotation and characteristics}

For the concepts easily confused with beliefs, different perspectives have different meanings for the analysis of beliefs. Wang Gongzhi, a Taiwan scholar, explored the definition of beliefs from the perspectives of sociology and psychology. From the perspective of psychology, belief is a kind of psychological state that people feel or are not aware of. From the perspective of sociology, belief is a kind of persistent attitude, value and ideology formed by people under the influence of social cultural and economic factors, which will be changed with the changes of society. With the different orientation and focus of research on teaching beliefs, the connotation of teacher beliefs is different, but educational beliefs, teacher beliefs and teaching beliefs are mixed with each other. Generally speaking, teacher beliefs mainly include teacher efficacy, the nature of knowledge, the reasons that motivate teachers to produce certain behaviors, self-perception and self-worth, self-efficacy and beliefs about some specific subjects.

In intelligent teaching, teacher's belief has multiple meanings. Some researchers regard teacher's belief as self-efficacy of technology use, while others regard teacher's belief as a combination of self-efficacy, belief in the value of technology, and belief in the use of technology to teach and learn. In this study, the beliefs of teachers in intelligent teaching mainly include teachers' views on the participation of technology in teaching, teachers' sense of self-efficacy, and their understanding and attitude towards the role of themselves in the classroom in the process of using artificial intelligence technology to assist teaching.

\subsection{Characteristics of teacher belief in intelligent teaching}

The characteristics of teachers' beliefs in intelligent teaching are mainly teachers' cognition of technology change teaching and teachers' technology view. The creation of artificial intelligence environment provides teachers with a transition from tradition to liberalism. Teachers use technology to change teaching, create rich intelligent teaching environment, and cultivate students' self-learning ability. All aspects of the complex connotation of teachers' beliefs in teaching, but in the intelligent teaching system, is more of a focus on the teacher's view of technology, intelligent technology for a particular application teaching situation, if choose "teachable willing education software and online teaching class, the teacher through" homework help platform to collect students' work and assessment, Using intelligent learning guidance software "super Star learning Pass" to upload learning materials, through scientific data for students' learning situation analysis, grasp the class students' learning progress and other use of intelligent teaching software to assist teaching. 


\section{Research idea}

From the perspective of teachers, teaching readiness is the degree to which teachers are inclined to accept or use intelligent technology to integrate into formal or informal learning activities, which may be related to personal teaching experience, teaching environment or cognition and attitude towards teaching of technological change. Teachers' intelligent teaching preparation is an explicit behavior of teachers' beliefs, which can be used to evaluate the technical views in teachers' beliefs and provide evidence for the factors that influence teachers' beliefs.

\subsection{Research objection}

To better promote the integration of intelligent technology and teaching, understanding the teaching readiness of front-line practical teachers is a key factor for the integration of intelligent technology into teaching. By exploring the teaching preparation state of front-line practical teachers in the context of artificial intelligence technology assisted teaching, and the real feedback of teachers on the use of intelligent technology, the influencing factors of teachers' beliefs in the process of intelligent teaching are explored. From the perspective of teacher professional development, this paper tries to put forward a development strategy for teachers to use intelligent technology to better improve the teaching effect, promote teachers' behavior from "information" to "intelligent", and make the convenience of intelligent technology from information technology discipline to multi-discipline.

\subsection{Research methods}

This research mainly focuses on the research on the status quo of teachers' teaching preparation in intelligent teaching and the influencing factors of teachers' beliefs. It adopts qualitative research methods, takes the researcher himself as the research tool, uses interview method to collect data, and uses induction method to encode and analyze the interview transcripts. From the perspective of teachers, the effect and influencing factors of the integration of artificial intelligence technology into teaching reform are explored.

The degree of teachers' mastery of the new concept of artificial intelligence can be summarized through the degree of teachers' mastery of the unique nouns in the field of artificial intelligence. Then judge teachers' understanding of intelligent teaching through their familiarity with some terms derived from the integration of intelligent technology and teaching. Teacher behavior is the manifestation of teacher beliefs. The teaching strategies and methods chosen by teachers and the teaching objectives set when designing courses with the participation of artificial intelligence technology can represent teachers' acceptance of the participation of technology in teaching and their cognition of their own roles. In this study, teachers' teaching readiness was summarized through their understanding of artificial intelligence teaching, the frequency of teaching assisted by intelligent teaching software, and the changes in teaching design.

By interviewing teachers themselves about the obstacles and challenges they encounter in teaching with intelligent teaching software, the influencing factors of teachers' beliefs are summarized, which are mainly divided into internal factors and external factors to explore and summarize.

\subsection{Data collection}

This study uses the method of targeted sampling and interviews five teachers who are willing to participate in the survey. The five teachers are distributed in different regions and teach different subjects, but they all use intelligent teaching software to assist teaching. The basic information table is shown in Table 1.

In this study, the research object was informed of the research purpose, research content, research plan, anonymous processing and recording data processing method when contacting the research object, and the full consent was obtained. In addition, the interview outline was presented to the interviewer before the experience and interview, and the privacy of the interview content was guaranteed, and their opinions were asked. This study is mainly a process of communication between the interviewer and the researcher about research questions, and the average time of communication with each interviewer is about 40 minutes. All interviews were recorded and all recordings were transcribed verbatim.

For the study of the influence factors of teachers' beliefs, this research USES Nvivo11.0 text of all the interviewee interview three-level coding analysis, the researchers for the interview transcripts, word for word, reading comprehension, extract the key nodes from words, and according to the relationship between the nodes to establish a generic, and after the comparison and analysis of the relation between generic, The core category is "the motivation of choosing intelligent teaching software to assist teaching”. 
Table 1. Basic information table of the research object

\begin{tabular}{|c|c|c|c|c|c|c|}
\hline object & $\begin{array}{l}\text { The degree of educational } \\
\text { informatization in the area }\end{array}$ & $\begin{array}{l}\text { Years as } \\
\text { a teacher }\end{array}$ & professional & $\begin{array}{l}\text { Professor } \\
\text { subject }\end{array}$ & $\begin{array}{c}\text { The information } \\
\text { technology capability } \\
\text { of the object }\end{array}$ & $\begin{array}{l}\text { Intelligent soft- } \\
\text { ware used }\end{array}$ \\
\hline$* * \mathrm{LI}$ & poor & 24 & teacher & $\begin{array}{c}\text { Junior high } \\
\text { school biology }\end{array}$ & weak & Zuoyebang \\
\hline$* * \mathrm{JIE}$ & developed & 3 & teacher & $\begin{array}{l}\text { Primary school } \\
\text { Chinese }\end{array}$ & strong & $\begin{array}{l}\text { Leljiaolexue, } \\
\text { Zuoyebang }\end{array}$ \\
\hline$* *$ NA & poor & 2 & teacher & $\begin{array}{l}\text { High school } \\
\text { Chinese }\end{array}$ & strong & DingTalk \\
\hline **YING & developed & 26 & teacher & $\begin{array}{l}\text { High School } \\
\text { Information } \\
\text { Technology }\end{array}$ & strong & $\begin{array}{l}\text { Tencent zuoye, } \\
\text { NET Ease } \\
\text { LOFTER }\end{array}$ \\
\hline$* *$ YAN & developed & 2 & teacher & $\begin{array}{l}\text { Primary school } \\
\text { Science }\end{array}$ & strong & Seewo, Dingtalk \\
\hline
\end{tabular}

\section{Analysis of research results}

After in-depth communication with the five interviewees, the transcripts of the interview recordings were analyzed in depth and specifically. The status quo of teachers' teaching preparation is summarized from the aspects of teachers' teaching behavior, their proficiency in the use of teaching software, and their views and understandings on the teaching of technological change. For the obstacles and challenges encountered in intelligent teaching, teachers can further summarize from two categories: internal factors and external factors.

\subsection{Status of teachers' teaching preparation for carrying out intelligent teaching}

In schools in areas where the development of educational informatization is more developed, teachers are mostly optimistic about the teaching of technological change and are willing to try different types of intelligent educational teaching software. The school has partnered with educational technology companies to run a large number of technical professional training courses to show teachers how intelligent teaching software can help in the classroom. The school actively promotes mutual help among teachers, and teachers with high proficiency in teaching software are the first to lead other teachers to learn intelligent technology and apply it in the classroom. Teachers themselves have higher learning enthusiasm for intelligent teaching, actively observe the model classroom, and gradually change the cognition of their own role. Transition from traditional classroom to constructivism classroom, from teacher-centered to student-centered, and change their own teaching strategies, such as adopting project-based teaching, prompting students to use intelligent teaching software to search for cutting-edge knowledge to complete learning tasks.

In regional schools where the development of educational informatization is relatively backward, the participation of technology in teaching is relatively low, and there are generally more elderly teachers. Teachers mainly use the single function of the teaching software, such as completing homework and punching in, releasing the important and difficult knowledge on the day of teaching, etc. Although the school policy supports teachers to actively try to use artificial intelligence technology to change teaching, the number of times and scale of relevant technical training are small, and the participation of teachers is not high. Teachers with a long teaching experience are more inclined to traditional classroom teaching and have less enthusiasm for the teaching effect of technological change teaching. Such teachers often have rich experience in teaching practice, pay attention to the transmission of theoretical knowledge, and use the traditional teaching method of "writing on the board + theoretical explanation". They are not optimistic about the transformative effect of technology in teaching. The diversity and complexity of intelligent teaching software also challenge the operating ability of such teachers.

Compared with long teaching (20 years), young teachers are more proficient in intelligent teaching software, and more able to adapt to the change of their role in the classroom, from the leader to the guide. Encourage students to use the learning materials provided in the software to complete tests and improve their self-learning ability.

\subsection{The influencing factors of teacher beliefs in the context of intelligent teaching}

\subsubsection{External factors}

Current situation of school teaching resources. Through the analysis and induction of the interview results of five 
teachers, the teachers generally believe that the hardware resources of their schools are the driving factors of carrying out intelligent teaching. In the regional schools with weak overall strength, the hardware equipment configuration is not perfect, and the teachers' experience and practice of intelligent teaching are very lacking. The degree to which schools attach importance to the development of educational informatization and the investment in intelligent teaching equipment determine the contact opportunities between teachers and intelligent teaching, and then affect the degree of recognition of teachers to intelligent teaching. For example, a school with smart classroom can enable students to use tablet computers in class to complete the task of group cooperation and searching for information, so that students will be more motivated to learn in class, master knowledge more correctly and experience more truly.

Technical training course. In schools with a low level of educational informatization, teachers are not proficient in the operation of teaching software, which will further lead to teachers' resistance to the use of intelligent technology teaching software. Schools cooperate with educational software companies to develop corresponding technical training courses for teachers to help them learn and master the use of teaching software.

Difficulty in integrating artificial intelligence technology and disciplines. Teachers are limited by the characteristics of the subjects they teach, and the degree of difficulty in combining artificial intelligence technology is different. For example, in Chinese, teachers can only provide audio or video for students to watch, which makes it difficult for students to create a real situation and experience the charm of ancient poems. However, science courses can be well integrated with artificial intelligence technology. Teachers publish learning tasks on the platform, simulate experimental scenarios, and make up for the defects of traditional classroom which can only be described in abstract theory. They can independently search relevant knowledge to solve problems through group cooperation.

Learning characteristics of learners themselves. According to the learning characteristics of the students in the responsible class, the teacher chooses whether to adopt the form of intelligent teaching and which functions in the teaching software. Primary school students in the lower age stage of independent learning ability is weak, mainly rely on parents to help. Teachers need to take parents' learning ability of intelligent teaching software into consideration and choose a teaching platform that is easy to operate and use. The function selection is relatively simple, such as only punching in homework or scoring students' performance in school. Senior students have strong autonomous learning ability, so teachers will choose teaching software with more complex functions and more associated databases.

\subsubsection{Internal factors}

Educational technology competency level. Although most of the frontline practical teachers participate in it training, their levels of information literacy are quite different, as are their levels of information technology and curriculum integration ability. Many teachers have poor basic skills of educational technology, which affects their application belief. According to the feedback from the interviewed teachers, many teachers can only use simple office software and produce monotonous and boring teaching courseware. Little is known about making audio and video related to subject courseware. Teachers believe that the use of courseware in teaching means the "integration" of artificial intelligence technology and subjects, which is a common misunderstanding among teachers.

Teachers with strong educational technology skills will actively explore the teaching network platform suitable for students through the evaluation of platform functions and the stability of the network system. Combined with the characteristics of the subject, intelligent technology can be truly integrated with the curriculum and students, and give full play to the autonomy of students.

Enthusiasm for learning intelligent technology. Whether teachers have the motivation to use artificial intelligence technology into the curriculum has a key impact on the success of the implementation of the new curriculum. When schools encourage teachers to design courses, if they do not consider the intrinsic needs of teachers' own development, they only publicize the reform of educational information policy and social requirements, which cannot enhance the motivation of teachers. Teachers lack internal motivation and have low enthusiasm for learning intelligent technology. They prefer offline traditional teaching, which makes it more difficult for them to improve their intelligent teaching ability.

Teacher's practical experience. Teacher's practical knowledge is the main knowledge base of teacher's professional development (Chen, 2020), although it is not as explicit as theoretical knowledge. However, when teachers accept the new teaching reform ideas advocated, the existing practical knowledge will play a filtering role, which greatly affects a series of teaching behaviors of teachers in the teaching process. Teachers of general subjects with rich experience in traditional teaching practice are mostly pessimistic about the application of intelligent technology in teaching, while teachers with less experience in practical teaching are more inclined to carry out the classroom supported by intelligent technology. 


\section{Strategies of teacher professional development in intelligent teaching}

The teaching management of schools should further strengthen the training of information technology for teachers, not only the teaching of simple computer software skills, but also how to truly integrate intelligent technology with teaching. Cooperation, can the school and the education software company to carry out the related technical operation training, for teachers to create the good environment of smart technology learning, provide a successful case teaching, guide teachers to think how to make use of artificial intelligence technology combined with traditional teaching effectively, how to make the abstract academic form into vivid and interesting education form, Then better make students in personality, thinking, wisdom level to get greater development. The school should also further create the campus intelligent education culture atmosphere, further implement the education information policy, increase capital input, improve the construction of school hardware resources. Create intelligent education environment, for example, create smart classroom, introduce more intelligent teaching software to assist teaching.

Considering to stimulate teachers' internal motivation, improving teachers' learning enthusiasm for intelligent technology. The propaganda should be strengthened to teachers, but the theoretical explanation should be reduced. From the perspective of practice, teachers can truly realize that intelligent teaching software can make up for the defects in traditional teaching. Schools can organize teaching competitions with prizes related to intelligent teaching among teachers, so as to promote teachers to change their attitude towards teaching with technological change, and transition from "information-based classroom" to "intelligent classroom".

From the perspective of social construction, the administrative departments of education should play a larger role in coordinating and guiding, especially for the underdeveloped areas of educational informatization. Local departments in charge of education can carry out more cross-school or even cross-provincial exchange and training activities, and at the same time, balanced and coordinated development of educational resources and teacher development should be achieved.

Teachers themselves should realize their own limitations in teaching, and update their knowledge, skill structure and educational teaching concepts. Related research shows that self-efficacy and teaching efficacy have a greater impact on the integration of information technology and curriculum in the belief structure of teachers. Although teachers hold a positive attitude towards "integration", there is a deviation from the actual teaching behavior. Teachers can combine classroom experience with self-reflection and practice according to the group of students they teach, the teaching environment and their own teaching style. Teachers can adjust their teaching behavior step by step, constantly evaluate the teaching effect in the teaching process, and then achieve the recognition of advanced teaching concepts.

\section{Conclusion}

The deep reason for the inefficiency of the use of teachers' educational technology is that teachers have not established and accepted the new belief of learner-centered technology integration and teaching innovation. Teachers' acceptance of intelligent technology into teaching is influenced by both external and internal factors. Whether teachers choose to use high-level technology to improve their teaching will be influenced by teachers' own cognition of the teaching of technological change, the overall intelligent teaching cultural atmosphere of the school, the hardware equipment resources of the school, their own teaching practice experience and the development of technical vocational training. In intelligent teaching, teachers' beliefs are manifested as a series of teaching behaviors of teachers, and teachers have changed their roles in the classroom. Through the medium of intelligent technology, students' cognitive development and learning innovation can be deeply promoted (Xiong, 2014). According to Becker, "Generally speaking, low-level technology application is often associated with teacher-centered practice, while higher-level technology ap-

plication is associated with student-centered or constructivist practice” (Lv, 2008). Stimulate the internal motivation of teachers, take into consideration the internal needs of teachers, and combine with the national teaching reform initiative, promote teachers to gradually change their roles, step forward from teacher-centered classroom to student-centered classroom, and realize the transition from low-order information-based teaching ability to high-order intelligent teaching ability.

\section{References}

Becker and Jay, H. (1994). How exemplary computer-using teachers differ from other teachers: implications. Journal of Research on Computing in Education.

Chen. J. C. (2020). Reform of law Practice Teaching in the Era of artificial intelligence [J]. Shan Dong Social Sciences, 2020(11): 86-90+96. 
Fu, M. R. and Wang, Q. (2017). Heuristic Metaphor analysis: a new method of foreign teachers' belief research [J]. Shanghai Research on Education, (08), 75-79.

Li, W. and Lin, J. X. (2012). A survey of the relationship between it teachers' teaching beliefs and teaching behaviors. e-Education Research, (09), 36-40+53.

Lin, X. Q. and Huang, R. H. (2008). Study on the Application patterns and Obstacles of Information Technology teaching for primary and secondary school teachers. China Educational Technology, (03), 31-36.

Liu, D. J., Du, J., Jiang, N., and Huang, R. H. (2018). The trend of integrating artificial intelligence into school education. Open Education Research, (04), 33-42.

Lu, L. T. (2008). Analysis of curriculum Implementation and its influencing factors-from the perspective of teachers. Continue Education Research, (08), 148-150.

Lv, L. H. (2008). Teacher teaching beliefs: an important factor influencing technology integration in teaching activities. China Educational Technology, (04), 16-20.

Xiong, B. Z. (2014). The influence of teachers' beliefs on the integration of information technology and mathematics curriculum. e-Education Research, (05), 87-90.

Yu, G. L. and Xin, Z. Q. (2000). Teacher belief and its significance to teacher training. Educational Research, (05), 16-20.

Zhang, Y., Zhang, X. Q., and Liu, D. Z. (2011). An analysis of the current situation and influencing factors of teachers' teaching beliefs in the information technology environment. China Educational Technology, (08), 110-113.

Zhang. D. Q. and Jin, J. X. (2006). Some new thoughts on the integration of information technology and mathematics curriculum. e-Education Research, (01), 55-57.

Zhang. Y. L. and Zheng, X. M. (2011). A Study of foreign language teachers' beliefs in the context of curriculum and information Technology integration. Foreign Language Education, (04), 52-56.

Zhu, Z. T., Peng, H. C., Lei, Y. H. (2018). Intelligent education: the practical path of intelligent education [J]. Open Education Research, (04), 13-24+42. 